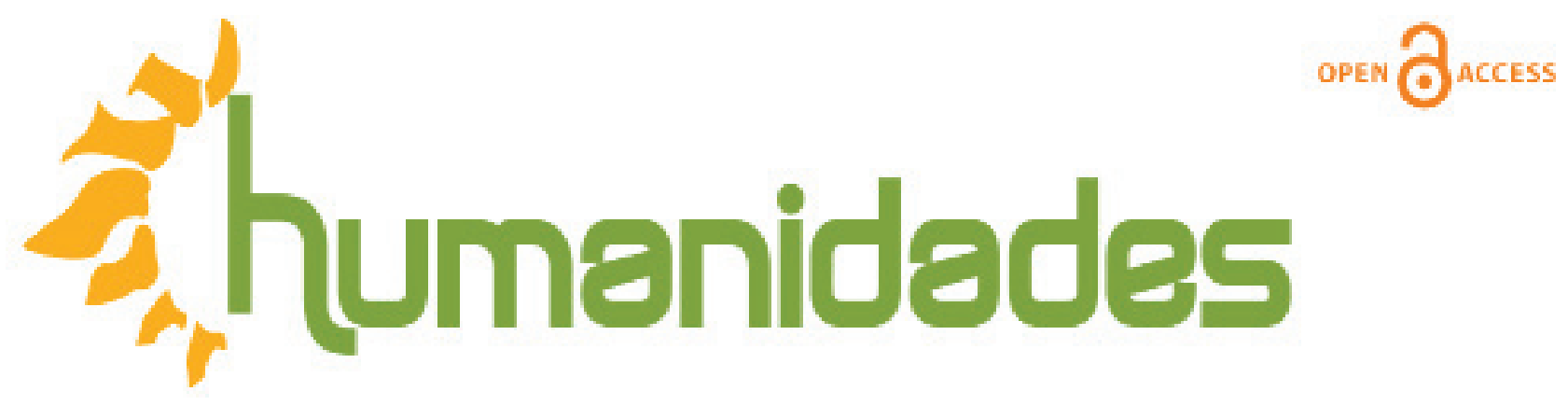

Revista de la Escuela de Estudios Generales, Universidad de Costa Rica

Enero-julio, 2019 •Volumen 9, número 1 • EISSN 2215-3934 • pp. 1-30

Recibido: 1-Agosto-2018 Aceptado: 11-Octubre-2018

\title{
El surgimiento de la literatura gauchesca en el Río de la Plata: cambio social y negociaciones culturales (1770- 1820)
}

DOI: https://doi.org/10.15517/h.v9i1.35335

\section{Jaime Antonio Peire}

Doctor en Historia. Instituto de estudios históricos. Universidad Nacional de Tres de Febrero-Consejo Nacional de Investigaciones Científicas y técnicas (CONICET), Argentina.

Correo electrónico: jpeire@untref.edu.ar ó jaimepeire@yahoo.com.ar

Todos los derechos reservados. Universidad de Costa Rica. Esta revista se encuentra licenciada con Creative Commons. Reconocimiento-NoComercial-SinObraDerivada 3.0 Costa Rica. Correo electrónico: humanidades@ucr.ac.cr/Sitio web: http: //revistas.ucr.ac.cr/index.php/ humanidades 


\section{El surgimiento de la literatura gauchesca en el Río de la Plata: cambio social y negociaciones culturales (1770-1820)}

La creciente importancia del Atlántico hizo que Buenos Aires fuera más relevante como puerto dentro de ese espacio que cambiaba de significado durante los siglos XVII y XVIII. Eso produjo un movimiento migratorio de población primordialmente indígena, mestiza y de castas, buena parte de la cual pasó a engrosar el "nuevo" espacio que abarcaba desde Rio Grande do Sul hasta la campaña rioplatense.

La literatura reflejó la emergencia de esos personajes que más tarde denominó gauchos o gaúchos captando su lenguaje y su vida en un género literario nuevo: la "gauchesca". Surgida en el último tercio del siglo XVIII en forma de composiciones, líricas menores, sainetes gauchescos, cielitos o diálogos, ella tendría una vigencia que duraría hasta hoy, aunque el "gaucho" sufrió grandes modificaciones en sus representaciones simbólicas y políticas. Este trabajo estudia el inicio de esa nueva literatura como el surgimiento histórico de un círculo identitario alternativo, quizás más igualitario, que no pudo ser ignorado, atendiendo a la responsividad del lenguaje y analizando su verosimilitud y negociación -aunque asimétrica- con las élites: éstas intentaban controlar esa mano de obra esencial en las estancias y el ejército.

\section{The Rising of the Gauchesca Literature in Río de la Plata: Social Change and Cultural Negotiations (1770-1820)}

The increasing importance of the Atlantic made Buenos Aires became more relevant as port of that space that was changing of meaning during the XVII and XVIII centuries. That fact produced an internal migration, primarily, of mestizo, indigenous and caste population, most of which circulated in that "new" space from Rio Grande do Sul to the Rio de la Plata area.

Literature reflected the emergence of these characters, later named as gaucho or gaúcho. It captured their language and life in a new literary genre : the "gauchesca". In the form of minor lyrical compositions, sainetes cielitos and dialogues, endured from the last third of the XVIIIth century until now, although the "gaucho" suffered great modifications in symbolic and political representations. This paper studies the beginning of this new genre - that cannot be ignored- as the historical birth of an alternative identity circle perhaps most egalitarian. It attends to the responsiveness of the language and analyzes its believability and negotiation with the elites, since them intended to control a workforce that was essential to the estancias but also to the army.
Palabras clave: literatura gauchesca, negociación e identidad, mestizaje y literatura, Río de la Plata

Keywords: gauchesca literature, negotiation and identity, miscegenation and literature, Río de la Plata 


\section{Introducción}

Durante los siglos XVII y XVIII la campaña rioplatense se desprendió de su rol principal de pertenencia de proveedor de mulas al espacio de arrastre altoperuano. Al cobrar mayor importancia el comercio atlántico Buenos Aires devino más relevante como puerto dentro de ese "nuevo" espacio que cambiaba de significado (Gelman, 2011). En paralelo con ese desplazamiento se produjo un intenso movimiento migratorio de población primordialmente indígena, mestiza y de castas, buena parte de la cual pasó a engrosar el "nuevo" espacio que abarcaba desde Rio Grande do Sul hasta la campaña rioplatense (Díaz, 1998; Sidi, 2015).

La literatura reflejó la emergencia de esos personajes que más tarde denominó gaúchos o gauchos captando su lenguaje y su vida en un género literario nuevo que hablaba de esa emergencia: la "gauchesca" (Ludmer, 1988). Esta nueva literatura surgida en el último tercio del siglo XVIII en forma de composiciones líricas menores, de sainetes gauchescos y de cielitos, tendría una vigencia que duraría hasta hoy, aunque el "gaucho" sufriera grandes modificaciones en sus representaciones simbólicas y políticas (Casas, 2014). Este artículo estudia el inicio de esa nueva literatura como el surgimiento histórico de un círculo identitario alternativo con una tendencia igualitaria atendiendo a la responsividad ${ }^{1}$ del lenguaje y analizando su verosimilitud y negociación -aunque asimétrica- con las élites: éstas intentaban controlar esa mano de obra esencial tanto en las estancias como en el ejército.

La literatura gauchesca fue, entre otras cosas, la respuesta cultural a un movimiento cuyo lenguaje y estilo de vida no solo no pudo ser ignorado, sino que involucró una larga negociación que terminó con un personaje mestizo o indígena como símbolo patrio al lado de los grandes próceres de una nación que presume de blanca y urbana.

Para el siguiente análisis utilizaremos la lírica y la dramática gauchesca del período estudiado. También trataremos de ponderar la responsividad del discurso (para decirlo en la estela bajtiniana) según el contexto, usando los periódicos y otras documentos pertinentes como discursos en torno a saberes, viajeros y otras fuentes extraídas de repositorios argentinos y españoles. No se trata de tomar literalmente lo que dice un personaje en un sainete o en un cielito o diálogo patriótico y 
transponerlo a la realidad "histórica", sino que más bien se trata de buscar, en el zócalo de su discurso, un cúmulo de significados que construye un sentido de pertenencia determinado. Este (sentido de pertenencia) flota en un proceso cultural que está transitando un camino, no sin accidentes, del barroco a la ilustración y el neoclásico, estilo artístico y literario que siguió al barroco colonial.

Las piezas que estudiaremos son sainetes, cielitos o diálogos patrióticos. El sainete es una composición dramática de menor extensión que fue, en el caso del gauchesco, el origen de esta literatura junto con los cielitos y los diálogos patrióticos. Solían usarse como entremés de piezas dramáticas serias. Con un lenguaje propio de los paisanos rurales expresado en octosílabos de rima asonante, extensión posiblemente tomada del romancero español - o del sainete barroco, también español - buscaban divertir y no tenían la solemnidad de los géneros mayores, según prescribe la regla de la poética de Aristóteles.

El cielito es una composición lírica octosilábica. Normalmente está escrita en redondillas, es decir, cuatro versos octosilábicos y es al mismo tiempo una danza: exigía una competencia para la cual los paisanos y los habitantes del ámbito rural estaban ya preparados (además de los citadinos). Son claramente una extensión lírica de la oralidad y se agrupan en estrofas de rima asonante. Los diálogos patrióticos comparten las características de las composiciones anteriores, salvo que están expresadas en forma de diálogos donde intervienen dos personajes y hay un desarrollo o cuento de algún suceso en particular o de alguna argumentación determinada.

En este trabajo estudiaremos el inicio de ese proceso tratando de focalizar el aspecto de negociación de un espacio que se pensaba como primordialmente dominado por los blancos, pero que se debió gestionar para insertar a un nutrido grupo de mestizos, castas e incluso indios para utilizarlos tanto en la guerra revolucionaria como también de mano de obra: no es una casualidad entonces que fuera este momento el del surgimiento de una literatura que se hizo famosa en el mundo entero: la literatura gauchesca. En general, están escritos como romances que van pronunciando cada uno de los personajes. Alguno de los cielitos y diálogos patrióticos están tomados solo como ejemplificaciones, pues exceden el período que nos proponemos tratar en este trabajo.Junto con ellos utilizamos otras fuentes, como periódicos o diarios de viajeros, que son pertinentes para conocer esta emergencia de la literatura gauchesca como expresión de un proceso sociocultural. 
El interés de esta propuesta radica en que esta emergencia literaria que estudiamos estaría señalando un círculo identitario donde, por un lado, el grupo coral gobernante blanco delimitaría los íconos, valores y sentimientos con los que habría que identificarse. Por otro lado, otro grupo, no tan coral, presentaba unos íconos y unos valores que resultaban políticamente incorrectos, lo anterior se daba al incluir a indios, afrodescendientes, mestizos, castas y otras mezclas "subalternas" que residían, predominantemente, en las zonas rurales. Esta gente era principalmente fruto de una inmigración interna que se había producido debido al creciente dinamismo socioeconómico de la campaña bonaerense y su incorporación al mundo atlántico, en consecuencia, dado los cambios generales que se estaban produciendo, dichas personas no podían, sencillamente, ser totalmente ignoradas.

\section{La temprana autonomía del espacio peruano y el crecimiento de Buenos Aires y la campaña}

Buenos Aires se había fundado por segunda vez en 1580. Era en realidad, en un principio, una villa muy pequeña con unos cientos de habitantes y una enorme campaña habitada por indios que habían conseguido desbaratar la primera fundación en 1536. Sin embargo, esta vez resistió la presión indígena y fue convirtiéndose en un lugar significativo, en parte porque era un puerto y en parte porque cumplía la función de escape para el contrabando de la plata producida en Potosí, de la cual la Monarquía no podía tener control por su carácter fronterizo. Este lugar era además el enlace entre la ciudad más importante: Asunción -hoy capital del Paraguay- con la Península.

Ya a partir de la década del 20 del siglo XVII la pequeña villa negociaba con la Monarquía para obtener un reconocimiento de esta, de su importancia estratégica y de la legitimidad de su poder: dado que era una comunidad natural -una república, los manuales de política barroca traducían polis por república- debía darse una organización autónoma capaz de insertarse en la amplia y policéntrica Monarquía católica. Aunque la lucha entre la élite de la pequeña villa y la burocracia monárquica duró largo tiempo, esta última tuvo que reconocer esa legitimidad y la función esencial que aquellos habitantes cumplían para el Rey, función que ningún otro grupo podía realizar. Buenos Aires utilizaba la misma mirada política monárquica para autolegitimar el poder de su élite y de su existencia funcional y necesaria dentro de un todo mucho mayor (Amadori, 2015). 
Buena parte de la historiografía colonial argentina de la segunda mitad del siglo XX, en torno al paradigma marxista, giraba alrededor de la relación entre la producción potosina y la conexión o desconexión con el espacio rioplatense. Pero el desarrollo de la historiografía en las siguientes décadas ampliaría estas perspectivas. Para Halperín Donghi el desmarque del Río de la Plata del espacio peruano habría sido, en buena medida, a partir de la creación del Virreinato de ese nombre. Pero las investigaciones más recientes han demostrado que Buenos Aires comenzó su trayectoria de autorreferencialidad ya en las primeras décadas del siglo XVIII, en buena medida de la mano del contrabando (Moutoukias, 1988; Halperín Donghi, 2005).

Buenos Aires creció poco a poco en el siglo XVII al ritmo del crecimiento del comercio atlántico y pasó de tener unos 1500 habitantes en el año 1630 a tener unos 3000 en 1700. Ya en el siglo XVIII el crecimiento de Buenos Aires fue más acelerado, hasta que la corona española decidió en 1776 crear otro Virreinato ascendiendo a ciudad capital del Virreinato y dejando a Potosí dentro de su órbita, invirtiendo los términos que hasta el momento habían imperado. Esto aceleró el crecimiento económico y la migración hacia Buenos Aires que tenía en ese entonces unos 10.000 habitantes. Para el año 1810, cuando la movilización "popular" se había iniciado, Buenos Aires contaba con unos 40.000 habitantes. Todavía era una aldea, pero su poderío político y económico había crecido considerablemente (Díaz, 1998; Sidi, 2015).

Esto aceleró el crecimiento económico y la migración hacia Buenos Aires que tenía en ese entonces unos 10.000 habitantes. Para el año 1810, cuando la movilización “popular" se había iniciado, Buenos Aires contaba con unos 40.000 habitantes. Todavía era una aldea, pero su poderío político y económico había crecido considerablemente (Díaz, 1998; Sidi, 2015).

Buenos Aires se sumó al boom comercial atlántico y al ciclo de las revoluciones atlánticas declarando su independencia (junto con el resto de las provincias "interiores" que la secundaron), inicialmente con la conformación de la "Primera Junta" (primer gobierno "patrio") y después, en 1810, entrando en guerra con la Monarquía hispánica. Pero podría decirse que el ciclo revolucionario comenzó con una movilización “popular”, no en contra, sino a favor de la Monarquía hispánica cuando en 1806 y 1807 los bonaerenses derrotaron un doble intento de invasión de un ejército inglés de unos trece mil hombres. 
Esta movilización "popular" exigida por las circunstancias, sin embargo, continuó hasta 1820 cuando las provincias del antiguo Virreinato derrotaron al ejército de Buenos Aires extinguiendo la antigua unión encabezada por Buenos Aires. Todavía faltarían unas cuatro décadas para que de todo ese confuso conjunto político emergiera en algo parecido a una nación: "Argentina".

Pero todo este proceso político muy brevemente relatado tuvo un correlato sociocultural menos conocido. En los primeros decenios del siglo XVII comenzó una inmigración lenta pero estable, a la cual los porteños llamaban "internas", esta inmigración se dio desde las provincias del Río de la Plata, de la Banda Oriental de este río y de lo que es hoy la Provincia de Río Grande Do Sul del Brasil, que tenía mucho que ver con el contrabando, para ese entonces todavía una frontera en disputa con la Corona española.

Este proceso migratorio se aceleró en el siglo XVIII cuando ya era evidente que España no sólo no tenía la supremacía marítima para controlar el comercio con sus colonias americanas, sino que el comercio por contrabando superaba al comercio legal y las élites locales exigían, a partir del control de este comercio, un lugar en las decisiones políticas regionales dentro del ejercicio del poder global en el interior de la Monarquía hispánica.

El proceso demográfico ha sido estudiado pormenorizadamente por Marisa Díaz quien afirma que "si la campaña bonaerense fue protagonista de un asombroso poblamiento entre 1744 y 1810 no menos vertiginoso fue el aumento demográfico de la ciudad de Buenos Aires" que se quintuplicó. Díaz considera que "este incremento acelerado se debió fundamentalmente al aporte migratorio, tanto de contingentes de esclavos como de europeos y de individuos provenientes del interior (...). Esto constituyó, sin duda, una inyección de riqueza y de vida, lo que se advirtió efectivamente en el espacio urbano" (Díaz, 1998, p.8). Las personas que migraron a la ciudad de Buenos Aires provenían, siguiendo los estudios de Díaz, de la misma campaña, Paraguay, Córdoba y Santa Fe, Cuyo, Perú, Alto Perú, Banda Oriental, Tucumán, Santiago del Estero, Catamarca, La Rioja, Salta y Jujuy (Díaz, 1998, pp.16-18). 
Pero quizás la parte más interesante para nuestro trabajo es el origen étnico de estas migraciones. Lo primero que la autora resalta es el aporte de los esclavos que no aparecían en la enumeración anterior. En el principio del período estudiado es importante el aporte de la propia campaña mayoritariamente blanca, o mejor, inscripta como blanca. Pero mientras más se acerque el foco hacia 1810, más será el aporte de otras etnias y, sobre todo, más el porcentaje de población cuyo origen se ignora y que, según información cualitativa, serán indígenas, afrodescendientes, mestizos, pardos; además, hubo un proceso de "blanqueamiento".

Las actas parroquiales de matrimonio no resuelven las carencias de los padrones. Díaz concluye que "es posible pensar que los numerosos grupos que provenían de regiones del interior fueran indios o mestizos y que arribaban a Buenos Aires, una ciudad muy cercana a la frontera, donde la clasificación étnica era más flexible que en otras ciudades de las áreas centrales de las colonias españolas" (Díaz, 1998, p.22). La autora sugiere un "cambio social, que involucraría a amplios sectores de la sociedad de Buenos Aires", definido a partir de las transformaciones en las identidades étnicas y culturales (Díaz, p.31).

Las actas parroquiales de matrimonio no resuelven las carencias de los padrones. Díaz concluye que "es posible pensar que los numerosos grupos que provenían de regiones del interior fueran indios o mestizos y que arribaban a Buenos Aires, una ciudad muy cercana a la frontera, donde la clasificación étnica era más flexible que en otras ciudades de las áreas centrales de las colonias españolas" (Díaz, 1998, p.22). La autora sugiere un "cambio social, que involucraría a amplios sectores de la sociedad de Buenos Aires", definido a partir de las transformaciones en las identidades étnicas y culturales (Díaz, p.31).

Ese cambio social que, según la autora, incluye un registro social amplio, mirado no ya desde el punto de vista demográfico sino sociocultural, se hace particularmente significativo cuando a la dinámica propia de esa sociedad y esa cultura se le agrega un ingrediente que acelera los tiempos y los cambios: las guerras; guerra y ww emergencia de la gauchesca es una secuencia significativa a la hora de comprender y explicar ese proceso especifico acotado en un espacio y un tiempo: el Río de la Plata entre 1776 y 1820. 


\section{Surgimiento de la gauchesca: el gaucho-soldado}

En medio de este panorama sociocultural (y étnico) y de estos cambios identitarios profundos alguien hizo su aparición en el escenario: la literatura que hoy denominamos gauchesca.

Hay que señalar que desde el punto de vista cultural se estaba incrementando también en el Río de la Plata la circulación -cada vez más amplia a medida que nos acercamos a los albores del siglo XIX-de los impresos y de pliegos sueltos que son la continuación de los cantares de gesta y del romancero español. Esto contribuyó a formular un espacio en el que esta cultura "popular" impresa "se constituyó como un ámbito en el que la oralidad y la escritura se interpenetraron, permitiendo que los distintos subgéneros [como por ejemplo el sainete gauchesco], perviviesen a través del tiempo en España y América en espacios concomitantes sucesivos" (Chicote, 2013, p.122).

Josefina Ludmer ha señalado, lúcidamente, que al tener que llevar a los gauchos a la guerra revolucionaria no había otra opción que darles una entrada legítima en el panorama social-oficialmente monopolizado por los blancos-al permitir el acceso del registro verbal de los gauchos al estatuto de lengua literaria" (Ludmer, 1988, p.30); pero Ludmer olvidaba una guerra anterior que fue el verdadero puntapié inicial de la gauchesca: la guerra contra Portugal por el control de Colonia de Sacramento.

Entonces no parece fruto de una casualidad sino más bien de una causalidad esta aparición, para nosotros quizás algo abrupta, pero que en realidad no lo fue tanto: hubo otros acontecimiento bélicos que Ludmer no menciona, los cuales son las dos invasiones inglesas mencionadas con anterioridad que también produjeron una abundante producción literaria - culta y popular- que aquí no estudiaremos por razones de espacio y porque, en rigor, no conocemos que se haya generado literatura gauchesca en ella. Pero algo significativo en este caso es la importancia del registro de la lucha de los afrodescendientes, pardos e indios en la victoria española (Peire, 2010, p.236). 
Al tiempo que el Virrey Pedro de Cevallos luchaba su propia guerra en el año 1776, cuando hizo su primera aparición la gauchesca, un sargento peninsular que participaba de ella -suerte de Garcilaso de la Vega- escribía en décimas octosilábicas la suya propia describiendo lo que veía o creía ver. Lo primero que dice y llama mucho la atención, pues después será retomado por la gauchesca emergente, es la belleza del paisaje; una suerte de belleza arcádica:

Si yo pudiera explicarte/ de aquel Pays lo frondoso,/ lo fértil lo deleitoso,/ se, que habías de admirarte:/ Pues todo de parte a parte/ es un Jardín, un Hechizo,/ un terrestre Parayso,/ y un Prodio (sic) [prodigio?] superior/ bien haya el divino Author,/ que tan divino lo hizo ${ }^{2}$.

El sargento no ocultaba su admiración de viajero por el exotismo de lo que relataba subrayando cierta forma idílica de compartir los bienes y de la igualdad, la disposición para el combate y, sobre todo, la falta de amor por la propiedad: los caballos y las reses eran usados por todos, aunque tuvieran dueño. Se mostraba ya aquí, en estos versos, la idealización de una vida que nunca existió tal vez, pero imaginada o en todo caso relatada. En ese país, anotaba el sargento con asombro:

qualquiera soldado Infante/ dexa de serlo al instante,/ y se pasa a ser montado:/ para el más leve recado,/ que a un sirviente se le ofrece/ a donde bien parece/ pilla un caballo corriendo,/ y aunque el dueño lo esté viendo,/ ninguna pena merece. ${ }^{3}$

Algo parecido sucedía, según el mismo relato, con el alimento vacuno:

Las volas, cuchillo y lazo,/ en el dicho país infiero,/ que mucho mas que el dinero/ para comer son del caso:/ p[ue]s cualquiera que de paso/ se le antoja alguna res/ la bolea por los pies,/ el lazo le arroja al cuello,/ entra el cuchillo a degüello,/ y se la come después. ${ }^{4}$

Comían una parte y tiraban el resto para que lo devoraran los cimarrones, caballos vacas y perros que, según el sargento, había a montones y se llamaban cimarrones "por sus libres albedríos". 5 
Esta admiración por una cultura evaluada como algo maravilloso producido en un lugar bucólico revela una mirada flexible hacia las clases rurales menos favorecidas. Traza así un contraste con la que Alonso Carrió de la Vandera había asentado en 1777 en su libro El lazarillo de ciegos caminantes donde la cultura de los gauderios era tratada con menosprecio o condescendencia, contrariamente, a la actitud del sargento peninsular.A pesar de eso conservamos algunas coplas, aunque censuradas, que cantaban algunos de estos gauderios. Ya estas primeras coplas nos dicen algo que será retomado después: "Salga a la plaza esa tropilla/ salga también ese bravo,/ y salgan los que quisieren/ para que me limpie el r... [rabo]. En este contexto nada tiene de arcádico el paisaje ni de bucólica la copla: el contexto, bucólico o despreciativo, lo pone el horizonte semántico del que ve (Schvartzman, 2013, p.22).

Después de las victorias, sobre los portugueses, del Virrey Pedro De Cevallos en 1777 - que había entrado en contacto tanto con los gaúchos como con los gaúchos de Río Grande do Sul, algo que el sargento peninsular mencionaba- el canónico Baltasar Maciel compuso un pequeño romance titulado Canta un guaso en estilo campestre los triunfos del Excmo. D. Pedro Cevallos $(1777)^{6}$. Este es el momento considerado por algunos como fundacional de la literatura gauchesca porque Maciel le asigna al personaje un lenguaje "campestre". Maciel nunca utilizó la palabra "gaucho" aunque "huaso" es el equivalente a gaucho en Chile y es equivalente en el poema a gaucho posterior.

Julio Schvartzman es uno de los que ha reflexionado con más hondura sobre este momento fundacional de la gauchesca y su significado. ¿Por qué esta literatura rompe la tradición panegírica, la expresión "letrada" e inventa algo nuevo, arriesgado, política y literariamente incorrecto sumergiéndose en la oralidad? Hay respuestas diversas a este interrogante: una puede ser porque la oralidad llama la atención. Otra porque sería una forma de desdoblar el panegírico: escribe dos sonetos (en uno de los cuales interviene en La Eneida) y este romance.

Quizás la respuesta pueda estar en centrarse en el autor que lo hace: Maciel. Es un canónico (muere en el exilio en 1788), que conoce las intrigas virreinales e interviene en ellas, además, cuenta con una de las bibliotecas más importantes de 
la época colonial. Profesor del Real Colegio de San Carlos en la generación de la Revolución de Mayo, muchos de los participes de esta revolución asistieron a sus clases, en cuanto a la característica de su escritura Schvartzman se arriesga:

Algo no obstante lo impulsa a una escritura radicalmente diferente: ¿la emergencia de un malestar?, la sensación de una falta, la intuición de los cuerpos de la guerra y la escucha imaginaria de otras voces en las batallas lejanas de fronteras -voces semejantes a las que formaban un sordo rumor en la pequeña e inquieta ciudad o descollaban en el pregón repentino, o quizá a las que lo habrían abordado antes o después de alguna homilía?- Maziel (podemos conjeturar la excitación, el temblor, incluso el temor y la duda) escribe, por primera vez, algo que nunca ha leído en un millar de libros de su biblioteca ni en las epístolas y presentaciones ante obispos y funcionarios (Schvartzman, 2013, p. 26).

Pero Schvartzman arriesga hasta cierto punto. Está diciendo lo mismo que dice Ludmer para la emergencia de la gauchesca, solo que Ludmer soslaya a Maciel, al huaso y a El Amor de la estanciera en la emergencia de la gauchesca, colocando a Bartolomé Hidalgo en ella. Para Ludmer, sin embargo, el surgimiento de la gauchesca se debe a algo que va en el mismo orden que sugiere Schvartzman: la utilización de los cuerpos del hombre rural en las campañas militares y de su lenguaje -utilización del género, de su voz- para integrarlo en las luchas revolucionarias.

Para Ludmer, incluso, el sentido del género [gauchesco] no es otro que el pasaje de la delincuencia a la civilización. La relación que tiene el uso del cuerpo del gaucho en la guerra con la voz es inmanente a la participación del gaucho en la guerra (y como mano de obra en las estancias): "porque tiene armas debe tener voz o porque tiene armas toma otra voz". Utiliza esa voz como un arma: es lo que define, para Ludmer, el género gauchesco (Ludmer, 1988, pp.22-24).

No diremos tanto: aquí no discutimos el "sentido" del género gauchesco viéndolo -como lo pretende hacer Ludmer- desde una visión global de él, sino que nos ocupamos, más bien, de la emergencia. Esa emergencia se da en dos momentos en que hay dos guerras: no parece casual entonces. Quizás haya una relación. Pero ésta no puede establecerse sin estudiar empíricamente qué es lo que dice esa voz. 


\section{3. ¿Solo una transgresión literaria?}

Ludmer enfatiza, sobre todo en las notas, la relación entre los estados y los cuerpos siguiendo a Michel Foucault. Sin desmentirlo, nosotros pretendemos enfatizar fenómenos desde otro ángulo. Para nosotros, lo importante está en el quiebre de la lengua escrita y la atención en el lenguaje oral en el que Maciel quedó atrapado, pues contenía una acumulación de sentidos, es decir, una visión global del mundo: otro mundo.

Y en la emergencia de este mundo, desde el espacio público, por medio de los manuscritos - muy usados en la época- o por la circulación de impresos (Peire, 2008, p.135).

En primer lugar, aunque sólo sea circunstancialmente, la primera estrofa de la composición de Maciel marca algo que -como señalan los dos autores mencionados junto con Gloria Chicote- muy posiblemente era una fórmula utilizada para comenzar un relato con la guitarra (dado que se encuentra en otros contextos geográficos desde el medievo) y que, al mismo tiempo, es la primera estrofa del Martín Fierro, alrededor de una centuria después: “Aquí me pongo a cantar”. Esta forma de comenzar es el equivalente de "Había una vez" de forma oral o "Erase una vez" de forma literaria: una manera evocativa que a la vez suspende el tiempo y deja al oyente preparado para llenar su imaginación con lo que cantará el personaje que templa la guitarra.

Lo que llama la atención es el modo atrevido de encarar el panegírico del Virrey Cevallos: "He de puja el caballero,/ y bien vaya toda su alma,/ que a los portugueses jaques/ ha zurrado la badana". He de puja es un sucedáneo evidente de "hijo de puta". Entonces esto sonaría: "Que hijo de puta el caballero" (El Virrey Ceballos) de tan buen general que es. Es una forma antifrástica de elogio (es decir, afirma lo contrario de lo que quiere decir: el insulto como alabanza).

Como se sabe, la literatura gauchesca expresamente pretendía nutrirse de la oralidad de los gauchos. Pues bien: el canónico Maciel ponía en boca de este personaje que Pedro de Ceballos era un "hijo de puta" de tan buen general y persona que era: ¿se puede tratar a alguien de rango tan superior como un virrey de manera tan igualitaria? (Maciel, Azcuénaga y otros, 1971, p.14). 
Mucho más tarde, otro autor llamado Hidalgo y considerado el padre de la literatura gauchesca, corroboraría ese tono igualitario escandaloso, pero esta vez, insultando directamente a la institución monárquica, aún cuando antes la imagen misma del Rey era sacralizada.

En Cielito de la Guardia del Monte (1820) Hidalgo nos muestra su profunda antipatía por los reyes: Cielo los Reyes de España/ La puta que eran traviesos/ Nos cristianaban al grito/ y nos robaban los pesos" (Hidalgo, 1986, p.89). ${ }^{7}$

También lo hace en Cielito a la venida de la expedición del Río de la Plata (1819): Cielo, cielo que sí/ el rey es un hombre cualquiera/ y morir para que el viva/ la puta es una zoncera (Hidalgo, 1967, p.26). Y otra estrofa todavía más escandalosa perteneciente a Cielito del Bañado (1818): Vení hijo de puta y borra/ esta gran constitución/que empieza: no reconozco/ a Fernando y su nación ${ }^{8}$. Aquí ya no hay una antífrasis, sino que hay un insulto liso y llano.

En verdad el plano de igualdad con que el Virrey y luego el Rey son enunciados es bastante escandaloso; especialmente, en el segundo caso, es directamente brutal si se tiene en cuenta que pocos años antes la imagen del Rey debía recibir un reconocimiento cuasi sagrado. Este plano de igualdad -a pesar de las protestas finales del Romance de Maciel- es lo que nos parece interesante resaltar de la gauchesca primitiva, la cual más tarde continuará este rumbo fijado desde el principio.

Aunque, como se puede ver, los cielitos citados son posteriores, sin embargo, utilizan esa enunciación que nivela a todos de manera subversivamente igualitaria, lo que le valió a Hidalgo muchas dificultades. La élite coral porteña no veía con buenos ojos ese igualitarismo y lo trató de "oscuro montevideano" aludiendo a su condición -atribuida- de mulato. ${ }^{9}$

Pero lo que queda en el registro histórico al final del día, desde el elogio antifrástico hasta el insulto liso y llano, es un cambio en la expresión emocional que testimonia la verosimilitud de un recurso literario para expresar un desprecio a lo que antes se debía venerar en virtud de un igualitarismo distinto y preocupante para la élite que manejaría los destinos de la revolución. ${ }^{10}$ 
Esto se verifica en dos momentos muy claros desde el surgimiento de la gauchesca con Maciel e Hidalgo. El primero esboza las líneas que el segundo tomará y cuya mano firme le otorgará a ese surgimiento el carácter de una emergencia que, a partir de allí, ya no será más la mano solitaria de un letrado que toma un lenguaje oral y lo lleva al plano literario recogiendo un mundo, sino que será una celebración de la patria y de la Monarquía en la que, a veces también, habrá un reclamo enunciado en un brutal igualitarismo que -si bien introducido por Maciel de manera delicadano cayó bien a todos en su utilización subversiva posterior que -como veremosestaba lejos de ser casual.

\section{Sainetes gauchescos: civilización y barbaria}

Esta enunciación igualitaria es de un tenor algo diferente, lo que se puede ver en el sainete anónimo titulado El amor de la estanciera, a partir de ahora reconocido, en este trabajo, por las letras AE. Este primer sainete gauchesco que se representó en el pequeño teatrito de Buenos Aires fue escrito, probablemente, hacia 1780. El tenor diferente también está presente en el sainete anónimo, aparentemente de la Banda Oriental, escrito hacia 1810 y titulado El valiente fanfarrón y el criollo socarrón, reconocido, a partir de ahora y para efectos de este trabajo, por las letras CS. Estas dos obras son sainetes esponsales pues cuentan, fundamentalmente, una boda; además, están enlazados ya que en el segundo, CS, se casa la hija de quienes se casaron en AE. ${ }^{11}$

Es un igualitarismo que no desentona con una sociedad estamental (ni siquiera con una patriarcal, como lo era la sociedad rural, aunque de un carácter patriarcal no exento de matices matriarcales) sino que, más bien, juega con el sintagma "civilización y barbarie" que ya estaba esbozado por las famosas cartas pastorales del Obispo Antonio de San Alberto, publicadas en Córdoba, pero impresas en Buenos Aires, y presentes en las bibliotecas porteñas. ${ }^{12}$

Sin embargo, los sainetes gauchescos que analizaremos aquí, muy escuetamente, comparten esa enunciación igualitaria básica escondida en una presunta barbarie que los mismos sainetes desmienten de manera irónica jugando con el humor, lo cual resulta ser la contracara de las cartas de San Alberto. ${ }^{13}$ En efecto: para el obispo no servían para el estado loshombres que teniendolonecesario "para cubrirse yun caballo 
para correr, un lazo para enlazar, y un pedazo de carne para comer, todo lo cual en estos Paises es muy barato, y fácil de conseguir, ya les parece que lo tienen todo, y que han llegado á cuanto puede aspirar su valor y su fortuna" (San Alberto, 1782, p.78).

Lo primero que salta a la vista, en esta suerte de mundo al revés de los sainetes, es que el uso de la moneda es inexistente: la yerba mate se la regalan unos a otros y los protagonistas se quejan de lo que cuesta en la ciudad. Lo que es valioso, en realidad, es el saber vivir en un hábitat duro al que los personajes de la ciudad no están acostumbrados. En AE, el locuaz portugués (que había sido preferido al principio por la casadera y su madre, por el hecho de su riqueza, porque era pariente de un marqués, por su conocimiento de la ciudad y porque "es hombre de España"), pierde el favor de la muchacha porque entra en escena pidiendo una cama, pues un caballo lo ha derribado y le duelen los huesos y se le ha salido una muela (AE, p. 21).

El candidato local se lleva el favor de la casadera por los regalos que le hace, demostrando que, aunque hombre callado, tiene una delicadeza interior muy superior a la del candidato urbano que intenta casarse con la muchacha sin contar todavía con la anuencia del padre, lo cual desata un pelea. Algo parecido pasa en CS donde hay dos mujeres, una de ellas casada, que son pretendidas por dos hombres de ciudad, uno de los cuales es sacristán y roba cosas de la iglesia para cortejar a la muchacha soltera.

Tanto el portugués de AE como el sacristán de CS hablan una lengua incomprensible para los sencillos campesinos: a los citadinos no se les entiende nada en su media lengua, portugués uno, mal latín el otro. Esta manera de hablar es algo que utilizan para darsen importancia. En el CS, el personaje que corteja a la mujer casada está armado hasta los dientes. En los dos sainetes hay una lucha en donde la supuesta barbarie vence sin ninguna dificultad a la "civilización" con unas simples boleadoras y un lazo (CS, f14 vta.-15 vta).

Pero para llegar a entender que las virtudes campesinas son muy superiores a la supuesta civilidad de los citadinos hay que atravesar en los sainetes gauchescos una página de verdadera barbarie, lo cual es un cliché obligado por el género del sainete y, en este caso, por el subgénero gauchesco. Por ejemplo, los personajes se rascan a menudo (una mujer se rasca ¡con las dos manos!), se golpean, se insultan 
El surgimiento de la literatura gauchesca...

achacándose, entre otras cosas, la barbarie misma. En el CS, incluso, las mujeres dejan que se las corteje en secreto, la una siendo casada y la otra teniendo un candidato local muy claro y aceptable.

Sin embargo, todos los personajes de la ciudad, en definitiva, son rechazables para cualquier radar ético de quienes estaban escuchando en el pobre teatrito de Buenos Aires: atropellan la voluntad del padre, algo inaceptable, son soberbios, mentirosos, codiciosos, mujeriegos y, en definitiva, no están preparados para vivir entre las incomodidades del campo: su proposición de formar una pareja es en realidad inviable. ${ }^{14}$

Por detrás de esa barbarie rural donde se cuenta, por ejemplo, el viaje a la ciudad, hecho que es visto exactamente al revés con la óptica rural, a partir de una ronda de mate o en un palenque donde se ataban los caballos se esconde una civilidad diferente que es rural y que no sólo sabe vivir en la dureza del campo sino que, mirado atentamente, se vive con cierta comodidad y casi siempre con alegría. No hay, en realidad, una escasez material que los afecte: Juancho, el novio de AE conquista a Chepa trayéndole un caballo manso que usaba su madre para ir a misa (el equivalente a una salida al pueblo), quesos para la madre y manteca para el padre. Pero demuestra que es un conocedor de la vida rústica, que podrá mantener a Chepa sin que pase apuros materiales (AE, p.19).

No hay sacerdote que case a los novios, pero eso no es problema porque, sin ningún tipo de escrúpulos ni cuestionamientos religiosos, el padre siempre es el que los casa (también en los sainetes esponsales más tardíos) con una simple fórmula: "Dios los haga bien casados." A continuación se produce una declaración de los padres o de los mismos novios de cómo debe ser un matrimonio seguido de una sencilla fiesta campesina con músicos.

Sólo pocos años más tarde, el 'primer diario regular rioplatense, el Telégrafo Mercantil (TM), decía sobre la vida rural en comparación con la corrupción de las ciudades: "En la Campaña, en esta morada feliz y deliciosa donde sólo vive el hombre entregado a la laudable ocupación, aquí es donde se ve desde luego compensado este desorden moral por otras generaciones [de donde podemos inferir que hay como una compensación cósmica entre el desorden "moral" citadino y el orden rural] tanto más virtuosas cuanto son más ignoradas, y que están más lejos 
de los riesgos del aplauso. No teme no, el Labrador, al infame usurero, ni al avaro acreedor, y mientras que el ostentoso es arruinado en la agitación de sus vigilias, el dichoso habitador de la Campaña reposa tranquilamente sobre la almohada del sosiego" (TM, 30/1/1801).

Encontramos aquí la misma campaña arcádica y los mismos personajes que, cuando hace falta, parecen personajes bucólicos: cuando Juancho y Chepa se declaran su amor el verso octosilábico de lenguaje gauchesco rudo troca en endecasílabos que, por momentos, parecen compuestos por el poeta del siglo XVI Garcilaso de la Vega y que están totalmente fuera del alcance de los protagonistas: ¿qué ha sucedido? Pues ha sucedido que esa campaña es totalmente inventada y trasladada a la campaña bonaerense y puesta - de manera irónica, para enseñar con el humoren boca de unos campesinos irónicamente brutos. ${ }^{15}$

Dicha campaña estaba tomada de Virgilio y Horacio. El canónico Maciel tenía en su biblioteca las obras de Horacio y las Églogas de Virgilio traducidas: ¿pará qué las quería traducidas alguien que sabía leer perfectamente el griego? (Peire, 2008). Realizó en AE una transposición magistral de una campaña más propia de los hermanos Graco que la del paisaje triste que la campaña bonaerense de esa época podía ofrecer, con el fin de que - entre acto y acto de una tragedia- la gente se riera un poco y aprendiera que el ámbito rural no era, necesariamente, la barbarie y el salvajismo que muchos pensaban y que en las ciudades también había bárbaros (Maggio Ramírez, 2016, p.42).

Los sainetes gauchescos elevaban la apuesta en varios sentidos en el surgimiento de la literatura gauchesca: no sólo habría civilización en la ciudad, sino también "en la campaña honrada" (CS, p.17), tópico largamente discutido en el Río de la Plata. La ciudad en cambio es presentada como corruptora: algo que, según la visión idílica que se nos brinda, no sucede en el ámbito rural donde no hay ambiciones desmedidas y reinaría una teórica simetría social. Todo esto no sólo circulaba en manuscritos privados, sino que se representaba en el teatro de la ciudad y-como veremos a continuación- se publicaba en el periódico: estaba en una esfera pública que crecía día a día (Díaz, 2016). 


\section{La negociación asimétrica}

Apenas unos 20 años después, pero a 10 años de 1810, fecha en la que se produjera la Revolución de Mayo en Buenos Aires, posteriormente a que Maciel escribiera su AE el mismo Telégrafo decía algo que, leído hoy, parece increíble para la época: "Podrá acaso la República prometerse en gente de esta clase, unos ciudadanos virtuosos e instruidos, capaces de honrar a su patria con el esplendor de la virtud y de las Letras?" Algo que no sólo se refería a los hombres sino también a las mujeres: “¿que cabría esperar de una mujer de las clases bajas que no es respetada?: a pesar de su discreción, si no les reconocemos honra, no las estaríamos empujando de esta manera hacia un camino que la República no desea?" Y concluía triunfal pero de manera utópica: “Quizás llegue el tiempo en que viésemos regentar las Cátedras, y mandar un Ataque a aquellos mismos cuyos abuelos fueron nuestros esclavos. Hasta ese punto puede llegar un hombre si no le falta "el poderoso estímulo del honor" (TM, 27/6/1801).

El artículo está precedido por un estudio en donde se afirma que la "Sociedad Argentina" (una sociedad que debían formar los "sabios argentinos" para fomentar la ilustración y la civilidad, pero que la Monarquía no permitió) puede ser integrada por mestizos de español e Indio y los extranjeros naturalizados. La Memoria aclaraba de qué universo estaba hablando: todos "sabemos cuánta es la multitud, y variedad de razas, o castas de gentes que hay en América, que se juzgan y tienen por viles e infames, ya sea por derecho, ya por costumbre, o por abuso, tales son: negros, zambos, mulatos, mestizos, quarterones, puchuelos". 16

El artículo sorprende por su capacidad de proyectar una sociedad futura estable y adecuada al progreso ilustrado en una sociedad estamental. Al presentar la Memoria, el autor decía a sus "conciudadanos" que no podría sostenerse por mucho tiempo considerar "viles" a las castas. Esta situación, decía, es "sumamente perniciosa a la Religión y al Estado" (antes el sujeto de imputación de ese predicado era la República) y por ello debe "ceñirse a términos más estrechos" (TM, 27/6/1801). 
Lo que más sorprende es el argumento por el cual sostiene que esta situación es dañina: hiere los sentimientos del honor en lo que debiera ser el resorte principal para que en la persona se vieran "arrebatado del noble entusiasmo del honor": de hacer cosas aún heroicas. El razonamiento sería: el tratar a una persona de vil e infame hiere sus "sentimientos de honor y de virtud"-verdaderos o imaginadosque pudieran convertirlos en ciudadanos al servicio de la religión y de la patria.

Sin embargo, en el mismo diario sorprende encontrar voces contrarias a una visión de la campaña y de sus habitantes tan idílicos, pastoriles, agrícolas y ganaderos como las voces que sugieren los sainetes -que no deben ser tomados literalmente de ninguna manera-y también sorprende, el hecho de que se muestren aspectos que preocupaban a la élite porteña: el control de la mano de obra y de la circulación de las personas de lo que la conocida "papeleta de conchabo" es una prueba bastante concluyente.

Una carta aparecida en el Telégrafo firmada por un Infausto Pastor, que sostendrá una polémica por el poco o mucho éxito de la evangelización en la campaña, sugiere que en las Estancias los "buenos hacendados” establezcan pequeñas capillas: "Este es un remedio que al pronto debería tomarse en mi sentir, y aún provisionalmente señalar Parroquias interinas, distribuidas por toda la Campaña, en las Estancias de los vecinos pudientes a quienes podía el Gobierno auxiliar con algunos Milicianos o Tropa [obsérvese la mayúscula] que recogiesen vagos de los innumerables que hay para los trabajos públicos". En la Campaña reina una "absoluta y entera relajación de costumbres" (TM, 1/10/1801).

Entonces, parece claro, que estos discursos utópicamente igualitarios, a seber: los discursos pastoriles proto-gauchescos (si se me permite el uso del término) y campesinos, las discusiones sobre el honor de las clases bajas y las discusiones sobre la mano de obra flotante en la campaña -étnicamente incierta: gente que habría que reunir por medio del ejército y darle un orden-, la discusión de la falta de mano de obra de los estancieros y para los "trabajos públicos", en sí, todos estos discursos juntos, constituía una parte importante de una negociación de significados y de asignación de funciones según las jerarquías que (aunque asimétrica y precisamente por ello) terminó instituyendo, en los términos de Cornelius Castoríadis, una república oligárquica que pronto se desvaneció en el aire. ${ }^{17}$ 
El surgimiento de la literatura gauchesca...

Una república oligárquica, sin embargo, donde las clases bajas habían aparecido como un nuevo y activo actor insoslayable y la literatura lo reflejaba(Di Meglio, 2006, pp.309-318). Las clases altas debían negociar con ellos porque no eran fácilmente manejables como parecía a la historiografía canónica. La emergencia de la literatura gauchesca temprana testimonia la aparición de esa nueva voz que ya es algo más que un simple partícipe necesario en el período estudiado (Fradkin, 2008, pp.63-65).

\section{Conclusiones}

Hemos visto cómo Buenos Aires y su hinterland al abrirse al comercio atlántico fue progresivamente adquiriendo una autonomía del espacio peruano con epicentro en Potosí: no sólo por el comercio a secas, sino también por el contrabando. Esto fue una negociación con la Corona nunca terminada, porque ella no podía -en rigor- imponer todas las condiciones dado que no dominaba el mar. Hasta que la Revolución terminó esta configuración, ese diálogo inestable y cambiante que, primero los Austrias, y después, los borbones, se habían esforzado por establecer. Para ese entonces la élite porteña -cuya cabeza visible era el Cabildo de Buenos Aires- se había hecho un lugar en la Monarquía española.

Esto sucedió antes de la creación del Virreinato del Río de la Plata en el primer tercio del siglo XVIII. Ese desmarque provocó también una lenta inmigración desde las provincias "internas" que se aceleró con la creación del Virreinato en 1778. A esa inmigración que incluía indígenas, mestizos y castas, que aparecen con más o menos claridad en los padrones, desde todos los confines del Virreinato, hay que sumarle la misma inmigración de la campaña bonaerense. Si bien en ella había registrados sobre todo blancos, también es verdad que los datos que tenemos permiten sugerir, fuertemente, que hubo un proceso de blanqueamiento, bien sea por las progresivas generaciones o bien porque las condiciones de empadronamiento, de las actas de bautismos o de matrimonios así permiten indicarlo.

A esto hay que sumarle una buena cantidad de afrodescendientes esclavos y libertos -y pardos- que habían entrado, o bien legalmente o bien ilegalmente, fuera para trabajar en el ámbito doméstico o con motivo de su necesidad como mano de obra en las cosechas. Su proporción dentro del total de la población era relevante si se tiene en cuenta los grupos de castas e indígenas que estaban ubicados en la base 
de la pirámide social: en el imaginario de la élite esa base social era conformada por distintos sectores étnicos aunque el esclavo fuera -en algunos aspectos- el más bajo.

El problema surgió cuando esa mano de obra-supuestamente pacífica y domesticadao esa gente que "vagaba" por la campaña sin someterse a la ley o simplemente estando lejos de quien tuviera jurisdicción para aplicarla con efectividad, tuvo que ir al combate. Esto produjo modificaciones culturales que, hoy por hoy, nos sorprenden. De un modo u otro hubo que negociar su colaboración si se quería reclutar un número de personas que realmente hicieran la diferencia evitando conflictos. Hubo que "verlos" y "mostrarlos": y al verlos se captó su lenguaje; una jerigonza que contenía o ya había fabricado un mundo de significados y se los había asignado al mundo citadino.

La expedición del Virrey Pedro de Cevallos en 1776 produjo el primer esbozo de lo que vendría después a manos del Canónico Maciel -esta vez con su firma- en un elogio a Cevallos por parte de estos personajes ("huasos"), en "su idioma", un sociolecto si se quiere. Esto es un reconocimiento; suponía también darle una voz a alguien que no la tenía y que se constituía en un actor relevante: por eso se le da la voz. Que esto es así nos lo confirma, como vimos, un sargento peninsular que es más específico todavía en el dibujo que traza de esa vida y que está hablando de una zona de habla portuguesa. Ese fue el nacimiento de la literatura gauchesca.

Lo que llama la atención en la descripción y en el lenguaje utilizado es la enunciación igualitaria o de tono igualitario que exhiben esas piezas literarias: algo que después se tornará en una brutal agresión contra la Monarquía. En efecto: llamarle "Hijo de puta" al Virrey Cevallos por más que sea un uso antifrástico es una manera drástica y osada de alabar sus condiciones militares de caudillo. Sin embargo, en pocas décadas, del uso antifrástico se pasó lisa y llanamente al insulto en la emergencia de la gauchesca.

Asimismo es remarcable, para una lectura atenta, la descripción de una campaña pastoril más propia de la literatura española del siglo XVI que de una campaña habitada por gente supuestamente elemental y bárbara hasta llegar a lo grotesco. Esto es un palimpsesto de una campaña bucólica inexistente en realidad, pero puesto en el acto por personajes chuscos que con ironía señalaban los defectos 
El surgimiento de la literatura gauchesca...

de la ciudad y nombraban las virtudes del ámbito rural, lo cual puede verse en los primeros sainetes gauchescos que invertían irónicamente, en clave de divertimento, civilización y barbarie.

Lo curioso es que esa visión utópicamente igualitaria, por un lado, y bucólicamente virgiliana, por otro, es sostenida en el primer periódico porteño, el Telégrafo Mercantil y continuada por el Semanario de Agricultura, industria y comercio. Claro que esta visión colisionaba con la de los estancieros que demandaban mano de obra barata pero que no podían controlarla, según esta perspectiva que desmentía a la otra, estancieros que consideraban que la gente que "flotaba" más o menos libremente eran todos unos facinerosos, o por lo menos, vagos peligrosos para la comunidad entera y debían ser puestos a disposición de ella (es decir de ellos) incluso por el ejército.

Veinte años más tarde, una segunda ola de participación de las clases bajas puso en movimiento otra vez este cúmulo de significados y asignaciones jerárquicas. La vacancia del Rey en España había promovido, en muchas partes de América juntas, autonomistas que tomaban en depósito la soberanía que él había resignado y, de hecho, la Junta de Buenos Aires envió tres ejércitos en "auxilio" de "sus" provincias “interiores" para liberarlas de la "opresión" de los "mandones" españoles que no representaban a nadie.

Esto significó la movilización de un gran número de personas provenientes de los sectores populares: pero en Buenos Aires esto no era nuevo. Esas masas ya estaban movilizadas y muchas de ellas no se habían desmovilizado aún por causa de dos invasiones inglesas en 1806 y 1807. Pero si se pretendía una movilización de una masa crítica de gente, que fuera efectiva a la hora de presentar combate, entonces, habría que negociarlo: el precio, sin embargo, resultó ser cada vez más alto dada la ineptitud o ineficiencia de las élites en manejar la situación y resolver sus propios conflictos. También había que pagarles sueldos y armarlos, lo que significaba desviar una parte de los recursos hacia sectores de cuya existencia poco se sabía y que -por descontado- no podían llevar armas. 
Esto llevó, en dos ocasiones, como lo hemos señalado, a tener que darles voz: y esa voz no siempre era coincidente con la autocelebración coral de las élites en la poesía neoclásica. Un nuevo género literario tuvo que albergar esa voz nueva que contenía una participación que era necesaria para ganar la guerra. Nada mejor que la literatura y el teatro para dejar aparecer, en el espacio público y en el nuevo mundo impreso, este nuevo género negociando esa participación del mundo rural y de la mano de obra tan importante para él como para los ejércitos en la guerra revolucionaria.

Esas negociaciones no terminaron bien: de ellas salió una república oligárquica que terminó en la pelea de Buenos Aires con las provincias ("sus" provincias) y la desunión de las "Provincias Unidas" que habían declarado su independencia. El problema no se resolvió cabalmente, desde el punto de vista institucional, sino hasta la década del 60 del siglo XIX y, desde el punto de vista de la realidad, hasta hoy mismo.

\section{Notas}

1 Entendemos por responsividad la "peculiar acentuación que asuma en mi enunciado, el género discursivo que elija para pronunciarla y, en definitiva, por las tonalidades de mi afectividad (...). Esta refracción de las miradas -y esta sí es una palabra batjiniana- es la que entramará la relación con el mundo y la posibilidad misma del conocimiento" (Arfuch, 2002, pp.65). En este caso, nos fijaremos en la acentuación y refracción de y hacia Maciel, especialmente, pero también, en en el caso de Hidalgo, a partir y desde los periódicos de la época y otras fuentes mencionadas en el texto que señalan y marcan en definitiva el surgimiento de la Literatura Gauchesca como una negociación social en cuanto que la respuesta y la refracción involucra grupos sociales diversos en el seno de una sociedad estamental, pero con una circulación comunicacional intensa (Díaz, 2016).

${ }^{2}$ Biblioteca Nacional de España, Ms.10.942. Relación exacta de lo que ha sucedido en la expedición a Buenos Ayres que escribe un sargento de la comitiva de ese año de 1778 en las siguientes Décimas, f. 146.

${ }^{3}$ Ibidem, f. 159 vta. 
El surgimiento de la literatura gauchesca...

\section{${ }^{4}$ Ibídem.}

${ }^{5}$ Ibidem, f. 160 vta.

${ }^{6}$ Para el tema de los gaúchos, Cfr. Schlickers, S. (2007). La composición de Maciel (o Maziel) puede consultarse en Maciel, J.B. (1979, pp.41-42.), recomiendo leer el Soneto panegírico que escribió: se comprende mejor cómo Maciel manejaba los dos registros: el culto y el "popular". Ponemos las comillas para subrayar que los que escribían estas composiciones líricas eran letrados.

${ }^{7}$ En el mismo cielito: "Eso que los reyes son/ imagen del Ser divino,/ es (con perdón de la gente)/ El más grande desatino.” (Hidalgo, 1986, p. 89). El antirealismo no es sólo propiedad de Hidalgo. El Cielito (1820) expresa: “Al amigo Ño Fernando/ vaya que lo lama un buey, /porque ya los tupamaros/no queremos tener Rey. La cursiva es nuestra (Becco, 1985, p.75).

8 En muchas ediciones puta troca en pucha, probablemente, copiando del puxa de Río Grande do Sul. La estrofa es del Cielito del Bañado (1818). El cielito titulado Un guardia del Monte contesta al manifiesto de Fernando VII y saluda al conde de Casa-Flores con el siguiente cielito en su idioma (1820), tiene una estrofa que podía tener un alto impacto en un auditorio acostumbrado a una sociedad estamental: Cielito cielo que si/ guárdensé su chocolate/ aquí somos todos indios/ y sólo tomamos mate (Hidalgo, 1967, p. 32).

${ }^{9}$ Diálogo patriótico interesante entre Jacinto Chano, capataz de una estancia en las islas del Tordillo y el Gaucho de la Guardia del Monte (1821). El diálogo contiene pasajes escabrosamente igualitarios para el momento. A guisa de ejemplo: "¿porqué nadie sobre nadie ha de ser superior?/ El mérito es quien decide" (Hidalgo, 1967, p. 43). Refiriéndose a la igualdad frente a la ley: "Pues yo siempre oí decir/ que ante la ley era yo/ Igual a todos los hombres (Ib.p. 49)." Refiriéndose a la desigualdad de la justicia: “¿Y esto se llama igualdad? La perra que lo parió.” (Ib. 50). A la libertad: "Y mientras no vea yo/ Que se castiga el delito/ sin mirar la condición,/ Digo que hemos de ser libres/ Cuando hable mi mancarrón. [Caballo]. (Ibídem, p. 45). Las críticas a Hidalgo (Hidalgo, 1986, p. 157 y ss). 
${ }^{10}$ Moscoso, J (2015, p. 17). Cfr. Para la Historia de las emociones y emocionología, Stearns, P. y Stearns, y Sterns, C.Z. (1985). Matt, S.y Stearns, P. (2014 pp. 1-13). Plampler, J. (2015).

${ }^{11}$ Anónimo. (1979). El amor de la estanciera, Buenos Aires, Centro editor de América Latina, pp. 9-31. ANÓNIMO, El valiente fanfarrón y el criollo socarrón, ([c.1810]). Archivo del Museo histórico de Montevideo, Uruguay, tomo 480 de manuscritos, en adelante, CS. Existen otros sainetes de lenguaje gauchesco tanto esponsales como patrióticos que aquí no mencionamos porque estudiamos sobre todo su emergencia, pero los hemos tenido en cuenta.

${ }^{12}$ Por ejemplo, San Alberto, Joseph de (1782) Carta Pastoral Que El Ilustrísimo y Reverendísimo Señor D. Fr. Joseph de San Alberto, Obispo del Tucumán Dirigió a todos sus diocesanos, Acompañando las Constituciones para las Casas de Niños Huérfanos y Huérfanas, fundadas en Córdoba, Capital de aquella Provincia, Córdoba 30 de abril de 1782, $n^{0} 79$.

${ }^{13}$ Para un análisis más detenido de estos aspectos cfr. Peire, J. (2016).

${ }^{14}$ Cfr. Ramón de la Cruz, La civilización, de donde está sacada la idea de que los rústicos pueden civilizar a los citadinos. Cfr. Maggio Ramírez, C.M. (2016). Civilidad imaginada. La construcción de la civilidad como signo identitario en la prensa tarco-colonial porteña. Un análisis del Telégrafo Mercantil, Rural, Político, Económico, e Historiográfico del Río de la Plata y del Semanario de Agricultura industria y comercio entre 1801 y 1803. Tesis doctoral. Buenos Aires, Facultad de Ciencias sociales, Universidad de Buenos Aires, p. 139.

${ }^{15}$ En un momento en CS el sacristán pronuncia un latinazgo escolástico (que no tiene nada que ver con la conversación que se está desarrollando) "Barbara Celarem" a lo que Chivíco, el novio, responde: Más bárbaro será el (porque están tratando de justificar que intentaban seducir a las mujeres en secreto sin la autorización del padre y -por supuesto- del marido. CS, f 13vta. Vale aclarar que Barbara Celarent era la forma que tenían los escolásticos de memorizar las distintas formas de silogismos de acuerdo con la cantidad y la cualidad de las premisas y la conclusión: el sacristán copia -y copia mal- una fórmula latina reconocida para denostar la barbarie de Chivíco. 
El surgimiento de la literatura gauchesca...

16 "Memoria sobre que conviene limitar la infamia a varias castas de gentes que hay en nuestra América”, Telégrafo Mercantil, 27 de junio de 1801.

17 En cuanto a la misma construcción del individuo - no digamos ya de una sociedad- es social e imaginaria: se instituye por medio de la puesta en escena de un imaginario que contiene significados que han sido negociados por la imaginación colectiva. Castoríadis, C. (1999, p. 121). En cuanto a las jerarquías cfr. Taylor, Ch. 2006, p.22. Hay una parte de la negociación de los significados que no tratamos aquí por una cuestión de espacio: la relación entre los significados y los afectos y/o emociones: algo que -después del Affective turn (Giro Afectivo)- se estudia, o al menos, se discuten en paralelo. Para el giro afectivo - para no alargar la citaEnciso Domínguez, Giazú y Lara, Alí (2014).

\section{Referencias}

Amadori, A. (2015). El comercio rioplatense y la construcción discursiva de un espacio político por el cabildo de Buenos Aires, 1610-1660. Histórica, 39 (2), 15-50.

Anónimo. (1979). El amor de la estanciera. En J. Bautista, J. Cruz y L. Ordaz (Eds.), El teatro argentino I: desde los origenes hasta Caseros. Buenos Aires: Centro Editor de América Latina.

Anónimo. (1810). El valiente fanfarrón y el criollo socarrón. Uruguay: Archivo del Museo histórico de Montevideo, tomo de manuscritos 480.

Arfuch, L. (2002). Dialogismo. En C. Altamirano (Dir.), Términos críticos de sociología de la cultura (pp. 664-668). Buenos Aires: Paidós.

Becco, H.J. (1985). Cielitos de la patria. Buenos Aires: Plus Ultra.

Casas, M.E. (2017). La metamorfosis del gaucho. Círculos criollos, tradicionalistas y política en la Provincia de Buenos Aires, 1930-1960. Buenos Aires: Prometeo.

Castoríadis, (1999). Figuras de lo pensable, Barcelona: Cátedra. 
Chicote, G. (2013). Poesía “popular” impresa e identidad. Los folletos gauchescos de la primea mitad del siglo XX en el área rioplatense. En A. Amadori y M. Di Pasquale (Coords.), Construcciones identitarias en el Río de la Plata, siglos XVIII-XIX (pp.121-133). Rosario: Prohistoria.

Díaz, M. (1998). Las migraciones internas a la ciudad de Buenos Aires, 17441810. Boletín del Instituto de Historia Argentina y Americana "Dr. Emilio Ravignani”, tercera serie, 16 y 17, pp. 7-31.

Díaz, C. (2016). Comunicación y revolución 1759-1810. Esfera y espacio público rioplatense. La Plata: Editorial Universitaria de la Plata.

Di Meglio, G. (2006). ¡Viva el bajo pueblo! La plebe urbana de Buenos Aires y la política entre la Revolución de Mayo y el rosismo. Buenos Aires: Prometeo.

Enciso Domínguez, G. y Lara, A. (2014). Emociones y ciencias sociales en el S.XX: La precuela del giro afectivo. Athenea Digital, 14(1), 263-288.

Fradkin, R. (2008). Cultura política y acción colectiva en Buenos Aires (1806- 1829): un ejercicio de exploración. En: ¿Y el pueblo dónde está? Contribuciones para una historia "popular" de la revolución de independencia del Río de la Plata (pp. 27-66). Buenos Aires: Prometeo.

Gelman, J. (2014). Los cambios en la economía atlántica entre los siglos XVIII y XIX. Desarrollo capitalista, globalización y desigualdad en América Latina. Nuevo Mundo Mundos Nuevos. doi: 10.4000/nuevomundo.66288.

Halperín Donghi, T. (2005). Revolución y guerra. Formación de una elite dirigente en la Argentina criolla. Buenos Aires: Siglo XXI.

Hidalgo, B. (1986). Obra completa. Montevideo: Ministerio de Educación y Cultura.

Hidalgo B. (1967). Cielitos y diálogos patrióticos. Buenos Aires: Centro Editor de América Latina. 
El surgimiento de la literatura gauchesca...

Ludmer, J. (1988). El género gauchesco. Un tratado sobre la patria. Buenos Aires: Sudamericana.

Maciel, J.B., Azcuénag, A.D. y otros. (1979). La literatura virreinal, antología. Buenos Aires: Centro Editor de América Latina.

Matt, S. y Stearns, P. (Eds.) (2014). Doing emotions History. Urbana, Chicago y Spriengfield: University of Illinois Press.

Maggio Ramírez, C.M. (2016). Civilidad imaginada. La construcción de la civilidad como signo identitario en la prensa tarco-colonial porteña.Un análisis del Telégrafo Mercantil, Rural, Político,Económico, e Historiográfico del Río de la Plata y del Semanario de Agricultura industria y comercio entre 1801 y 1803 (tesis doctoral, inédita). Universidad de Buenos Aires, Facultad de Ciencias Sociales, Buenos Aires, Argentina.

Moutoukias, Z. (1988). Power, Corruption and Commerce: "The making of the local administrative structure in seventeenth century Buenos Aires. Hispanic American Historical Review, Nueva York, Duke University Press 68(4), 771- 801.

Moscoso, J. (2015). La historia de las emociones, ¿de qué es historia?’. Revista Vínculos de Historia, (4), 15-27.

Peire, J. (2008). Bibliotecas tardocoloniales: leer la Revolución de Mayo en el Río de la Plata. Eadem Utraque Europa, (6), 107-153.

Peire, J. (2016). Políticamente incorrectos: sentimientos identitarios en la literatura rural Gauchesca. 1770-1828. Anuario del Instituto de Historia Argentina, 16 (2), 1-29.

Peire, J. (2010). Los sentimientos de pertenencia y su evolución en la producción literaria rioplatense entre 1767-1925. En M. Terán y V. Gayol (Eds.), La Corona rota. Identidades y representaciones en las Independencias Iberoamericanas (pp. 229-262). España: Castelló de la Plana, Universitat Jaume I. 
Plamper, J. (2015). The History of the emotions. An introduction. Oxford: Oxford University Press.

San Alberto, Joseph de. (1782). Carta Pastoral Que El Ilustrísimo y

Reverendísimo Señor D. Fr. Joseph de San Alberto, Obispo del Tucumán

Dirigió a todos sus diocesanos, Acompañando las Constituciones para

las Casas de Niños Huérfanos y Huérfanas, fundadas en Córdoba,

Capital de aquella Provincia. Madrid: Imprenta Real.

Sidy, B.L. (2015). Población y gobierno en el Buenos Aires colonial. Una aproximación al estudio sobre las tensiones generadas por el crecimiento demográfico en la ciudad (1740-1776). Revista Complutense de Historia de América, 41, 49-275.

Schvartzman, J. (2013). Letras Gauchas. Buenos Aires: Eterna cadencia.

Schlickers, S. (2007). Que yo también soy pueta. La literatura Gauchesca rioplatense y brasileña (siglos $X I X-X X)$. Madrid: Iberoamericana-Vervuert

Stearns, P. y Stearns, y Sterns, C.Z. (1985). Emotionology: Clarifying the History of Emotions and Emotional Standards. American Historical Review 90 (4), 813-836.

Taylor, Ch. (2006). Imaginarios sociales modernos. Barcelona: Paidós. 